\title{
Priming Stimulation Enhances the Depressant Effect of Low- Frequency Repetitive Transcranial Magnetic Stimulation
}

\author{
Meenakshi B. Iyer, Nicole Schleper, and Eric M. Wassermann \\ Brain Stimulation Unit, National Institute of Neurological Disorders and Stroke, National Institutes of Health, Bethesda, Maryland 20892-1430
}

Low-frequency $(1 \mathrm{~Hz})$ repetitive transcranial magnetic stimulation (rTMS) can depress the excitability of the cortex locally and has been proposed for the treatment of disorders such as schizophrenia and epilepsy. Some have speculated that the depressant effect is related to long-term depression (LTD) of cortical synapses. Because in vitro LTD can be enhanced by pretreatment of synapses with higherfrequency stimulation, we hypothesized that if rTMS depression had mechanisms in common with LTD, higher-frequency priming would increase it also. In 25 healthy volunteers in two experiments, we measured motor-evoked potentials (MEPs) from TMS of the motor cortex to define the baseline response. Subthreshold rTMS (6 Hz, fixed rate or frequency modulated) was used to prime the motor cortex, followed by suprathreshold $1 \mathrm{~Hz}$ stimulation for $10 \mathrm{~min}$ at just above the MEP threshold. Over the next $60 \mathrm{~min}$, we recorded MEPs every $10 \mathrm{sec}$ and found significant increases in the amount of cortical depression with both types of $6 \mathrm{~Hz}$ priming rTMS relative to sham. The MEP depression from $6 \mathrm{~Hz}$-primed $1 \mathrm{~Hz}$ rTMS showed no evidence of decay after $60 \mathrm{~min}$. Pretreatment with $6 \mathrm{~Hz}$ primes both $1 \mathrm{~Hz}$ rTMS depression and LTD. Although not conclusive evidence, this strengthens the case for overlapping mechanisms and suggests a potent new technique for enhancing low-frequency rTMS depression that may have experimental and clinical applications.

Key words: priming; transcranial magnetic stimulation; plasticity; motor cortex; long-term depression; treatment

\section{Introduction}

Transcranial magnetic stimulation (TMS) is a low-risk, noninvasive method for inducing electrical currents in restricted areas of the cerebral cortex in conscious humans. A few minutes of lowfrequency repetitive TMS (rTMS) delivered to the motor cortex at an intensity near or above the threshold for evoked muscle twitches produces a refractory state in which the electromyographic response to stimulation, the motor-evoked potential (MEP), is reduced in size (Wassermann et al., 1996b; Chen et al., 1997a; Touge et al., 2001), and its threshold is elevated (Fitzgerald et al., 2002). There is a general belief that this effect is cortical (Touge et al., 2001), and there is growing interest in using it to treat conditions including epilepsy (Tergau et al., 1999), focal dystonia (Siebner et al., 1999), and the auditory hallucinations of schizophrenia (Hoffman et al., 2003). Others (Kosslyn et al., 1999) have used $1 \mathrm{~Hz}$ rTMS to inhibit cortical areas in the investigation cognitive processes in healthy individuals.

Analogies have been drawn between the depressant effect of low-frequency rTMS and the well known in vitro phenomenon of long-term depression (LTD) (Christie et al., 1994), in which electrical stimulation of neurons at frequencies in the $1 \mathrm{~Hz}$ range produces a stable decrease in excitatory synaptic transmission. Horizontal (Hess and Donoghue, 1996) and vertical (CastroAlamancos et al., 1995) connections in the rat motor cortex are

Received June 4, 2003; revised Sept. 25, 2003; accepted Sept. 29, 2003.

M.I. was supported in part by the San Antonio Area Foundation (San Antonio, TX) and the Georgia State University (Atlanta, GA).

Correspondence should be addressed to Dr. Eric M. Wassermann, Building 10, Room 5N254, 10 Center Drive MSC 1430, Bethesda, MD 20892-1430.E-mail: WassermannE@ninds.nih.gov.

Copyright $\odot 2003$ Society for Neuroscience 0270-6474/03/2310867-06\$15.00/0 susceptible to LTD and could be activated by motor cortex TMS to induce a refractory state in which the output pathway of the MEP was depressed by a cellular or synaptic change. However, no experimental evidence in favor of an LTD-like mechanism exists at this point.

An important feature of in vivo LTD is the phenomenon of priming. Brief pretreatment with stimulation in the $5-6 \mathrm{~Hz}$ range greatly increases the ability of subsequent $1 \mathrm{~Hz}$ stimulation to produce a decrease in synaptic efficacy (Christie and Abraham, 1992; Abraham and Bear, 1996). Importantly, the priming stimulation can be so brief or mild that it has no detectable effects of its own on synaptic transmission. This phenomenon, during which previous neuronal activity modulates the capacity for subsequent plastic change, has been termed "metaplasticity" (Christie and Abraham, 1992; Abraham and Bear, 1996; Abraham and Tate, 1997; Abraham, 1999). To date, no physiological experiments have looked for metaplasticity in humans. However, in light of the animal evidence and the surface similarity of lowfrequency rTMS depression and LTD, there is reason to believe that priming stimulation designed to heighten the susceptibility of cortical circuits to synaptic depression might enhance the depressant effect of $1 \mathrm{~Hz}$ rTMS if they share common mechanisms.

In this study, we investigated the effect of $6 \mathrm{~Hz}$ priming on the depressant effect of $1 \mathrm{~Hz}$ rTMS in the human motor cortex. We hypothesized that $1 \mathrm{~Hz}$ rTMS would be more effective at depressing motor cortex excitability after priming with $6 \mathrm{~Hz}$ rTMS than after sham priming.

\section{Materials and Methods}

Subjects

Twenty-six healthy individuals gave written informed consent for the study, which was approved by the National Institute of Neurological 
A

\begin{tabular}{|c|} 
Test \\
\hline $0.1 \mathrm{~Hz}$ \\
$115 \%$ \\
threshold \\
\hline
\end{tabular}

$10 \mathrm{~min}$

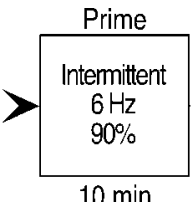

$10 \mathrm{~min}$

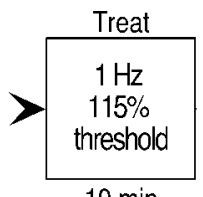

$10 \mathrm{~min}$

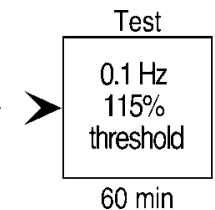

$60 \mathrm{~min}$

B $6 \mathrm{~Hz}||||||||||||||||||||||||||||||$

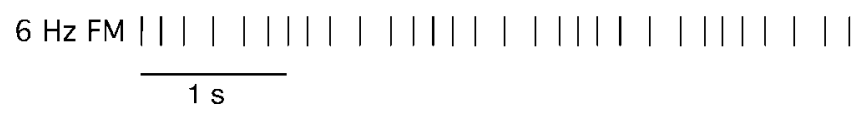

Figure 1. A, Flowchart showing the paradigm for experiments 1 and 2. B, Graphical representation of the constant $(6 \mathrm{~Hz})$ and frequency-modulated $(6 \mathrm{~Hz} F \mathrm{FM})$ priming stimulation patterns.

Disorders and Stroke Institutional Review Board. Subjects were interviewed and examined by a neurologist and found to be free of any significant medical or psychiatric illness or medications known to affect the CNS. Additional demographic data are given below.

\section{Experimental setup}

Subjects were seated with the right forearm and hand supported. The surface electromyogram (EMG) was recorded from the right abductor pollicis brevis (APB) and extensor carpi radialis (ECR) muscles. We chose to record from a physiological flexor and extensor in the hand and forearm to determine whether the effects of priming were present in muscles with different physiology (Lemon, 1993) and to make artifacts of limb positioning, etc. less likely. Subjects were instructed to maintain muscle relaxation throughout the study. The EMG was amplified, analog filtered ( $100 \mathrm{~Hz}$ and $1 \mathrm{kHz})$, digitized $(2 \mathrm{kHz})$ using a microl401 unit and Signal software (Cambridge Electronic Design, Cambridge, UK), and stored on a standard computer for off-line analysis. In each trial, the EMG was acquired for a total of $400 \mathrm{msec}$ with 100 msec of baseline before delivery of the stimulus. The absence of voluntary contraction was verified on-line by visual monitoring of the EMG and offline inspection of the individual traces. Trials with EMG activity in the baseline were discarded.

A Magstim Super Rapid stimulator (The Magstim Company New York, NY), which produces a monophasic pulse, and an 8 shaped coil with two $70 \mathrm{~mm}$ diameter windings were used for the first six subjects in experiment 1 . Thereafter, to avoid the problem of coil heating, a NeoPulse stimulator, which emits a biphasic pulse, and a coil consisting of a ferrous core wound with eight turns of wire (Neotonus, Atlanta, GA) were used for the subsequent 10 subjects in experiment 1 and all subjects in experiment 2.

Placement of the coil over the motor cortex was done by finding and marking the scalp site that was optimal for producing MEPs in the right APB on a tightly fitting cap with a chin strap. In all subjects, stimulation at this position produced smaller MEPs in the ECR as well. A custombuilt apparatus held the coil on a rigid arm and provided a chin rest for the subject. The position of the coil was monitored visually throughout the stimulation sessions.

\section{Testing TMS}

The MEP threshold was measured at the start of each experiment. This was defined as the minimum stimulus intensity required to elicit an MEP of $\geq 50 \mu \mathrm{V}$ in the relaxed $\mathrm{APB}$ on $\geq 5$ of 10 consecutive trials at least $5 \mathrm{sec}$ apart. After measuring the MEP threshold, we applied TMS pulses at an intensity of $115 \%$ of MEP threshold for $10 \mathrm{~min}$ to obtain a baseline measure of MEP amplitude. The timing of the individual stimuli was varied randomly by $\leq 20 \%$ around a mean frequency of $0.1 \mathrm{~Hz}$ to avoid rhythmicity. After each treatment (see below), $0.1 \mathrm{~Hz}$ TMS was again delivered at the same intensity for $60 \mathrm{~min}$ (Fig. $1 \mathrm{~A}$ ). It has been shown (Chen et al., 1997a) that stimulation at $0.1 \mathrm{~Hz}$ for periods of up to $1 \mathrm{hr}$ does not cause detectable effects on motor cortex excitability.

Treatment rTMS

Priming. In each session, after the baseline MEP amplitude determination, one of three types of priming stimulation was delivered for $10 \mathrm{~min}$. The types of priming were as follows: (1) $6 \mathrm{~Hz}$ rTMS, with the pulses occurring at a fixed frequency; (2) frequency-modulated $6 \mathrm{~Hz}(6 \mathrm{~Hz} \mathrm{FM})$ rTMS, with the frequency modulated through a range of $4-8 \mathrm{~Hz}$ each second (Fig. $1 B$ ). [Burst-modulated stimulation has excitatory effects, and so-called "theta-patterned" stimulation has become a standard procedure in in vitro studies to produce long-term potentiation (LTP) and prime LTD (Larson and Lynch, 1986; Larson et al., 1986).]; and (3) sham $6 \mathrm{~Hz}$ rTMS, with the coil activated at $6 \mathrm{~Hz}$ but placed with the back of the coil housing in contact with the head and the front tilted up at an angle. Under this condition, there was an auditory artifact but no MEPs could be produced with stimulation even at maximum intensity.

For priming, the TMS intensity was set at $90 \%$ of the MEP threshold. Subjects received either $6 \mathrm{~Hz}, 6 \mathrm{~Hz} F \mathrm{~F}$, or sham priming on different days separated by at least 1 week. The order of priming types was randomized and counterbalanced across subjects in each experiment. The details of the regimens are given below in the descriptions of experiments 1 and 2.

$1 \mathrm{~Hz}$ rTMS. After priming, we delivered $1 \mathrm{~Hz}$ rTMS at $115 \%$ of the MEP threshold for $10 \mathrm{~min}$ to induce MEP depression.

\section{Replication and the effect of priming dose}

To look for an effect of the priming dose, all three priming types were tested with two train lengths: In experiment 1,16 individuals (10 men; mean age, $37 \pm 8$ years; range, 23-49; two left-handed) were given 600 priming pulses ( 20 trains lasting $5 \mathrm{sec}$ separated by $25 \mathrm{sec}$ ). In experiment 2, nine different individuals (six women; mean age, $26.6 \pm 7.4$ years; range, 19-38; two left-handed) received 1200 priming pulses (20 trains lasting $10 \mathrm{sec}$ separated by $20 \mathrm{sec}$ ).

\section{Reaction time testing}

To screen for behavioral side effects of the combined treatment, we measured the auditory reaction time before and after each TMS session. Subjects were instructed to press the space bar on a standard computer keyboard by abducting the right thumb as quickly as possible in response to a click delivered at a random interval after a warning cue.

\section{Data analysis}

The reaction time was measured from the go signal (click) to the recorded key press. Data from before and after each rTMS session were compared within and across priming types and doses by repeatedmeasures ANOVA.

The measurement of the MEPs and the data analysis were entirely automated. The MEPs were measured peak-to-peak using Signal software (Cambridge Electronic Design), and the data were exported to Matlab (Mathworks, Natick, MA) or Statview (SAS Institute, Cary, NC) for additional analysis. The post-treatment period of each experimental session was divided into six 10 min epochs, and the mean MEP amplitude was calculated for each epoch in each individual. Because of the high variability in MEP amplitude from trial to trial and the skewness of the means when there are many "zero amplitude" responses (Fig. 2), we log-transformed the MEP amplitudes before analysis. This has been shown to restore the lower tail of the distribution under similar conditions (Wassermann, 2002).

To exclude significant differences in baseline excitability between sessions, the baseline MEP amplitudes were compared in each experiment by repeated-measures ANOVA. The effect of priming on the depressant effect of $1 \mathrm{~Hz}$ treatment was evaluated separately in the APB and ECR by repeated-measures ANOVA comparing baseline with the first $10 \mathrm{~min}$ epoch after treatment, with treatment (before vs after) and priming type as independent variables. To look at the persistence of depression after 1 $\mathrm{Hz}$ treatment, another set of ANOVAs was performed with time (10 min epochs 1-6 after treatment) and priming type as independent variables. The mean MEP amplitude data for each epoch were normalized across 

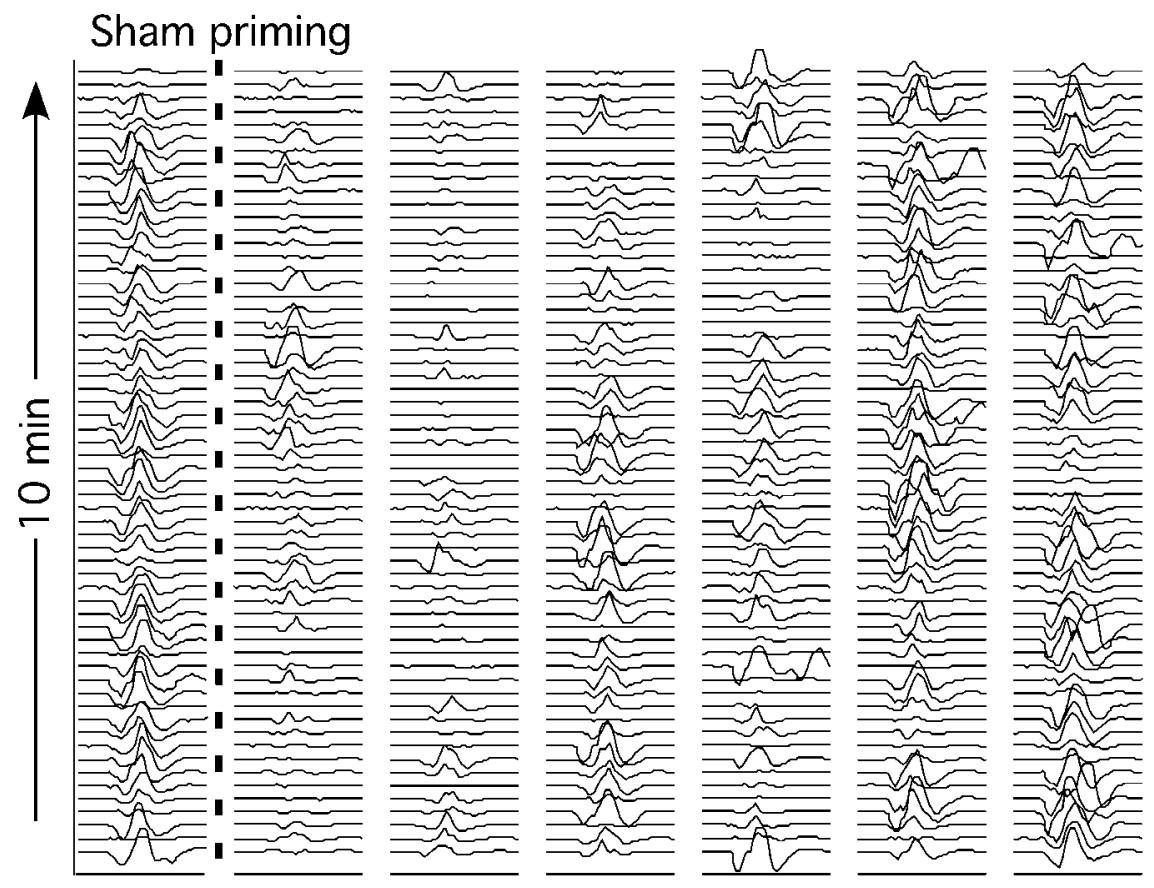

ing stimulator type as an independent variable to these analyses. To test for the effect of the dose of priming, the results of experiments 1 and 2 were compared for each muscle in separate ANOVAs. Post hoc comparisons were done with the Bonferroni-Dunn test. The threshold for statistical significance was set at $p<0.05$.

\section{Results}

After her first session (sham), one subject who was anxious and apprehensive during the study experienced a "heavy" feeling in the right hand after treatment, which recurred episodically for a few days. Her reaction time did not change with treatment, and there were no abnormalities on neurological examination. She was excluded from further participation, and her demographic and physiological data were not included. No other participants experienced any subjective effects of stimulation that lasted beyond the study session. There were no significant effects of treatment on reaction time either within experiments or after pooling all data. Nor did the MEP threshold change significantly within subjects across sessions; the mean never varied by $>0.5 \%$ of maximum stimulator output. There were no significant differences on any measure between the results from the subjects treated and tested with the Magstim and Neotonus stimulators.

\section{Experiment 1}

There were no significant differences between the MEP amplitudes in the pretreatment baseline between sessions in either muscle. The comparison of baseline with the first $10 \mathrm{~min}$ epoch showed significant depression of MEPs independent of priming type after the combined priming- $1 \mathrm{~Hz}$ treatment (Fig. 3) (main effect of treatment: APB, $F_{(1,29)}=32.7, p<0.0001$; $\left.\mathrm{ECR}, F_{(1,29)}=16.5, p=0.001\right)$. However, the effect was greater after $6 \mathrm{~Hz}$ and $6 \mathrm{~Hz}$ FM than after sham in both muscles (treatment $\times$ priming type interaction: $\mathrm{APB}, F_{(2,28)}=3.4, p=0.046$; ECR, $\left.F_{(2,28)}=4.5, p=0.02\right)$.

Post-treatment MEP monitoring was performed for $60 \mathrm{~min}$ in 11 of 16 subjects. In these individuals, both $6 \mathrm{~Hz}$ and $6 \mathrm{~Hz}$ FM priming decreased MEP amplitude after $1 \mathrm{~Hz}$ rTMS in both muscles relative to sham during the $60 \mathrm{~min}$ post-treatment period (Fig. 4) (main effect of priming type: $\mathrm{APB}, F_{(2,98)}=7.2, p=0.004$; ECR, $\left.F_{(2,98)}=8.0, p<0.03\right)$. Post hoc testing revealed significant differences when comparing $6 \mathrm{~Hz}$ and $6 \mathrm{~Hz} \mathrm{FM}$ with sham

subjects by dividing each value by the same individual's baseline mean MEP amplitude. Therefore, the baseline epoch was not included in the time course analysis. We also compared the data from the subjects in experiment 1 who were treated with each of the two stimulators by add- in both muscles (all $p<0.01$ ) but no significant differences between the two active priming types. There were no significant main effects of time or priming type $\times$ time interactions. 


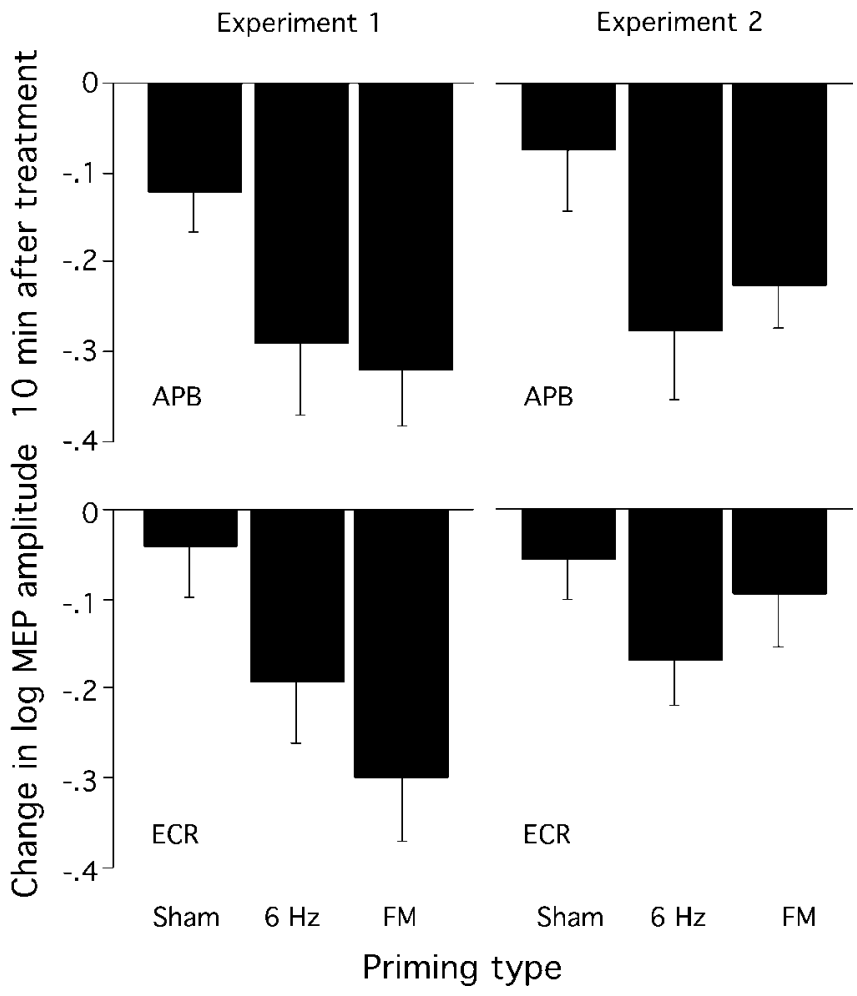

Figure 3. Graph of the change in MEP amplitude from baseline to the first $10 \mathrm{~min}$ after combined priming $-1 \mathrm{~Hz}$ treatment in the APB and ECR muscles for each priming type in experiments $1(n=16)$ and $2(n=9)$. Error bars show SE.

\section{Experiment 2}

There were no significant differences in the baseline MEP amplitudes between sessions in either muscle. Again, comparison of the baseline with the first 10 min epoch after treatment showed that priming- $1 \mathrm{~Hz}$ treatment significantly decreased MEP amplitude (Fig. 3) (main effect of treatment: APB, $F_{(1,15)}=18.4, p=$ 0.003 ; ECR, $\left.F_{(1,15)}=11.1, p=0.01\right)$. Although active priming produced more MEP depression than sham in both muscles (Fig. $3)$, the priming type $\times$ treatment interaction did not reach significance in either muscle in this analysis. However, in the $60 \mathrm{~min}$ after treatment (Fig. 4), the main effect of priming type was significant in both muscles $\left(\mathrm{APB}, F_{(2,78)}=3.8, p=0.04\right.$; ECR, $\left.F_{(2,78)}=5.8, p=0.01\right)$. The only post hoc comparison to reach significance after adjustment for multiple comparisons was between sham and $6 \mathrm{~Hz}$ FM in the ECR $(p=0.006)$. As in experiment 1 , there was no statistical evidence of wearing off (i.e., the main effect of time was nonsignificant) and there were no significant priming type $\times$ time interactions. Comparison of the two experiments showed no significant main effects of experiment or interactions of experiment with other factors.

\section{Discussion}

These results demonstrate that stronger depression of motor cortex excitability by $1 \mathrm{~Hz}$ treatment can be achieved if priming rTMS at $6 \mathrm{~Hz}$ precedes it. The difference from sham was present in a flexor and an extensor muscle at almost all points from 10 to $60 \mathrm{~min}$ after treatment in two experiments using two different groups of subjects. The reduction in average MEP amplitude of $\sim 30-40 \%$ was comparable with our own peak effects and those of other groups, but the lack of any sign of recovery at $60 \mathrm{~min}$ indicates an effect that is longer-lasting than reported previously (Touge et al., 2001).
Experiment 1

Experiment 2

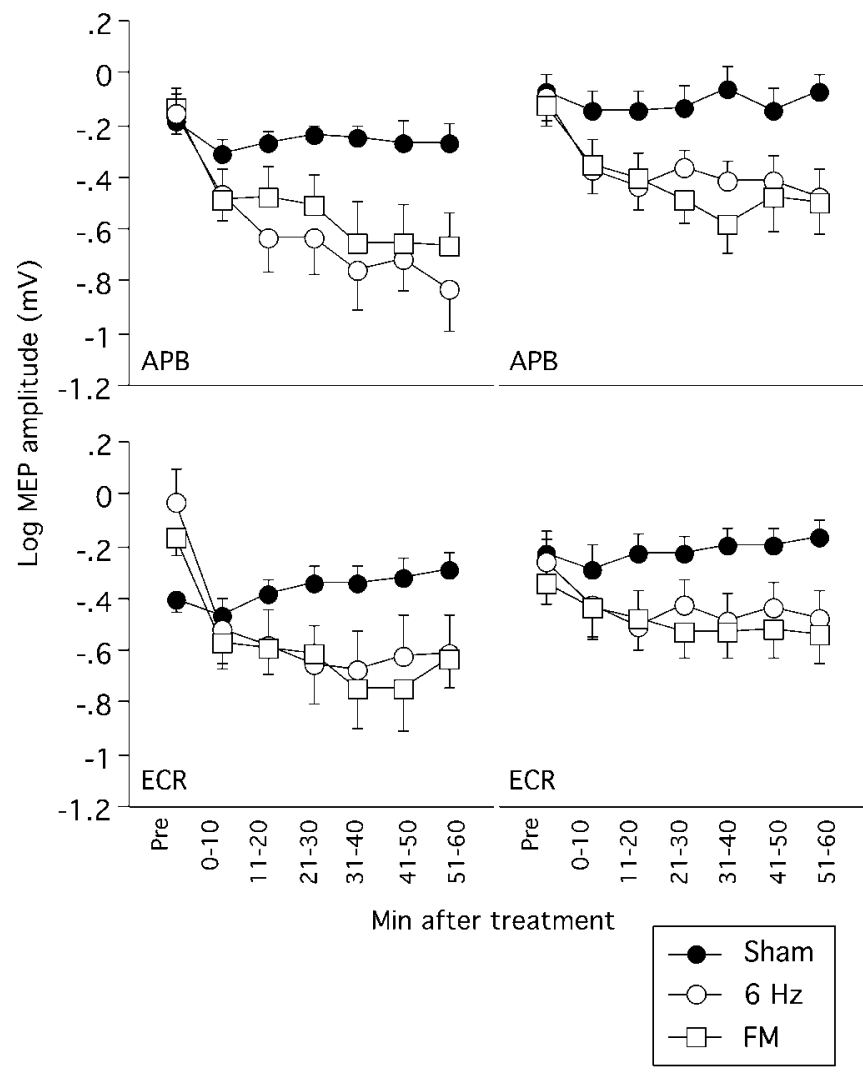

Figure 4. Plots show the averaged time course of depression after combined priming $-1 \mathrm{~Hz}$ treatment in the APB and ECR muscles for each priming type in experiments $1(n=11)$ and 2 $(n=9)$. Points represent mean log MEP amplitude in millivolts. Error bars show SE. Note that the change from baseline (Pre) to the first epoch $(0-10)$ in experiment 1 does not match the data in Figure 3 exactly because of the difference in numbers of subjects in the two analyses (see Fig. 3 legend).

A potential limitation of the data concerns the repositioning of the coil after sham stimulation, which might have introduced a systematic difference in the effectiveness of the $1 \mathrm{~Hz}$ treatment that followed. However, random error or bias in the replacement of the coil after sham would be unlikely to produce less apparent inhibition relative to baseline, because moving off the optimal site after priming would produce smaller MEPs in the posttreatment test phase, effectively mimicking inhibition. A suboptimal position for the baseline phase that was "corrected" after sham priming would have resulted in a group difference in the baseline MEP amplitude, which we ruled out statistically (see Results).

This study was designed to ask whether theta modulation of the $6 \mathrm{~Hz}$ priming stimulation might be more effective than constant frequency stimulation, but this was not the case. The lack of any discernable difference between the priming types suggests that any frequency in the $4-8 \mathrm{~Hz}$ range, through which the FM stimulation was modulated, might be as effective. We also note that the theta burst paradigm used for in vitro studies delivers high-frequency (e.g., $100 \mathrm{~Hz}$ ) electrical stimulation in bursts occurring at the theta frequency. How well our paradigm approximated these conditions, if at all, is a matter of conjecture at this point. Nevertheless, frequency modulation remains worth considering as an adjuvant technique in rTMS treatment studies.

It is also notable that increasing the length of the priming trains did not increase the MEP depression produced by subse- 
quent $1 \mathrm{~Hz}$ rTMS. This suggests that the effect of the combined treatments in experiment 1 may have reached a "floor," below which additional MEP depression was not possible. However, the study was limited by the fact that we only performed the test stimulation for a period of $60 \mathrm{~min}$, during which there was little if any wearing off of the depression under the primed conditions. Perhaps differences in the duration of the effect would have emerged in a longer observation period.

A remarkable feature of the motor cortex depression with 1 $\mathrm{Hz}$ rTMS is the lack of any readily detectable behavioral correlate. In previous studies (Wassermann et al., 1996; Chen et al., 1997a), we examined a variety of neuropsychological and clinical measures, but the only motor finding to emerge was an increase in finger-tapping frequency. Other manipulations that depress the MEP [for instance, the commonly prescribed $\mathrm{Na}^{+}$channel blocker anticonvulsants phenytoin (Chen et al., 1997b) and carbamazepine (Ziemann et al., 1996)] also have generally mild or nonexistent motor side effects at clinically effective doses, suggesting that the motor system compensates easily for changes in the excitability of the cortical output neurons. In testing simple reaction time, it was our intention to screen only for behavioral effects at the clinically significant level. More detailed or rigorous testing (for instance, a task requiring targeted movements without feedback) might have disclosed effects on motor behavior.

Although the primary purpose of this study was to look for a priming effect on $1 \mathrm{~Hz}$ rTMS depression, our findings also provide some support, albeit circumstantial, for the analogy between the depressant effect of $1 \mathrm{~Hz}$ rTMS in the human cortex and LTD in animals. LTD of motor cortex neurons by $1 \mathrm{~Hz}$ rTMS is plausible and has been invoked as an explanation (Touge et al., 2001). TMS activates the muscles via a trans-synaptic pathway (Thompson et al., 1989; Rothwell et al., 1991, 1994) that these and other results have shown is susceptible to modification by $1 \mathrm{~Hz}$ rTMS. Recently, Rioult-Pedotti et al. (2000) demonstrated learningrelated potentiation in horizontal connections onto layer II-III motor cortex pyramidal neurons along with conventional LTP and LTD in the same synapses. They proposed that such synaptic changes are responsible for the rapid reorganization of motor outputs in response to changes in input (i.e., motor learning). It is possible that $1 \mathrm{~Hz}$ rTMS causes alterations in these or other synapses in the motor cortex, possibly those directly onto corticospinal neurons, resulting in decreased neuronal excitability or synaptic efficacy along the pathway from cortex to spinal cord. The augmentation of the depressant effect of $1 \mathrm{~Hz}$ rTMS by priming at $6 \mathrm{~Hz}$ is the first physiological evidence in favor of an LTD-like mechanism for this change.

Touge et al. (2001), in arguing against LTD as the basis of rTMS depression, noted that the effect on MEPs disappears in voluntarily activated muscles, because if synapses directly in the path of the stimulus from cortical horizontal axon to muscle were modified, the MEP produced by a stimulus of a given intensity should be smaller after treatment regardless of whether neurons in the pathway are depolarized by voluntary drive. The more likely explanation, according to this view, is a decrease in the excitability (e.g., mild hyperpolarization or stabilization) of the corticospinal neurons themselves that could be overcome by sufficient voluntary drive, thereby restoring MEP amplitude. LTD, however, need not occur "in series" with the path of the stimulus from cortex to muscle to affect neuronal excitability. For instance, collateral intracortical pathways, such as those studied by Rioult-Pedotti et al. (1998, 2000), could exert an influence on the resting excitability of cortical output cells that would be swamped by voluntary drive. One might also note that in vitro LTD has not been tested under conditions analogous to voluntary activation of the modified pathway.

It has been observed that under some conditions, priming stimulation of synapses in vitro, especially by very strong stimulation, can lead to enhancement of long-term potentiation (Abraham and Bear, 1996; Abraham and Tate, 1997). A similar effect has been observed in humans during rTMS studies (Wassermann et al., 1996a; Chen et al., 1998), in which accidental seizures occurred unexpectedly after closely spaced series of stimulation trains that would have been safe if delivered in isolation. Our findings with subthreshold $6 \mathrm{~Hz}$ priming indicate that even very mild stimulation can alter the cortical response to later stimulation. This has implications for protocols designed to increase cortical responsiveness (for example, those used in the experimental treatment of depression and Parkinson's disease) (Wassermann and Lisanby, 2001) and for the safety of high-frequency rTMS in general.

Regardless of the mechanism of $1 \mathrm{~Hz}$ rTMS depression or $6 \mathrm{~Hz}$ priming, these results have considerable methodological importance. Low-frequency rTMS is being adopted successfully as a technique for making "temporary lesions" for the study of cognitive (Kosslyn et al., 1999; Hilgetag et al., 2001), sensory (Knecht et al., 2003), and motor cortical (Muellbacher et al., 2002) processes, to take only a few leading examples. Clinicians, too, are beginning to use the same procedures to depress pathologically overactive brain areas, most successfully in schizophrenia (Hoffman et al., 2003), but also in focal dystonia (Siebner et al., 1999), Tourette syndrome (Munchau et al., 2002), epilepsy (Tergau et al., 1999; Theodore et al., 2002), hemineglect after stroke (Brighina et al., 2003), and depression (Klein et al., 1999). Priming stimulation, which has been safe and easy to administer in our hands, could greatly improve the effectiveness of low-frequency rTMS as a tool for the laboratory and clinic.

\section{References}

Abraham WC (1999) Metaplasticity: key element in memory and learning? News Physiol Sci 14:85.

Abraham WC, Bear MF (1996) Metaplasticity: the plasticity of synaptic plasticity. Trends Neurosci 19:126-130.

Abraham WC, Tate WP (1997) Metaplasticity: a new vista across the field of synaptic plasticity. Prog Neurobiol 52:303-323.

Brighina F, Bisiach E, Oliveri M, Piazza A, La Bua V, Daniele O, Fierro B (2003) $1 \mathrm{~Hz}$ repetitive transcranial magnetic stimulation of the unaffected hemisphere ameliorates contralesional visuospatial neglect in humans. Neurosci Lett 336:131-133.

Castro-Alamancos MA, Donoghue JP, Connors BW (1995) Different forms of synaptic plasticity in somatosensory and motor areas of the neocortex. J Neurosci 15:5324-5333.

Chen R, Classen J, Gerloff C, Celnik P, Wassermann EM, Hallett M, Cohen LG (1997a) Depression of motor cortex excitability by low frequency transcranial magnetic stimulation. Neurology 48:1398-1403.

Chen R, Samii A, Canos M, Wassermann EM, Hallett M (1997b) Effects of phenytoin on cortical excitability in humans. Neurology 49:881-883.

Chen R, Gerloff C, Classen J, Wassermann EM, Hallett M, Cohen LG (1998) Safety of different inter-train intervals for repetitive transcranial magnetic stimulation and recommendations for safe ranges of stimulation parameters. Electroencephalogr Clin Neurophysiol 105:415-421.

Christie BR, Abraham WC (1992) Priming of associative long-term depression in the dentate gyrus by theta frequency synaptic activity. Neuron 9:79-84.

Christie BR, Kerr DS, Abraham WC (1994) Flip side of synaptic plasticity: long-term depression mechanisms in the hippocampus. Hippocampus 4:127-135.

Fitzgerald PB, Brown TL, Daskalakis ZJ, Chen R, Kulkarni J (2002) Intensity-dependent effects of $1 \mathrm{~Hz}$ rTMS on human corticospinal excitability. Clin Neurophysiol 113:1136-1141. 
Hess G, Donoghue JP (1996) Long-term depression of horizontal connections in rat motor cortex. Eur J Neurosci 8:658-665.

Hilgetag CC, Theoret H, Pascual-Leone A (2001) Enhanced visual spatial attention ipsilateral to rTMS-induced "virtual lesions" of human parietal cortex. Nat Neurosci 4:953-957.

Hoffman RE, Hawkins KA, Gueorguieva R, Boutros NN, Rachid F, Carroll K, Krystal JH (2003) Transcranial magnetic stimulation of left temporoparietal cortex and medication-resistant auditory hallucinations. Arch Gen Psychiatry 60:49-56.

Klein E, Kreinin I, Chistyakov A, Koren D, Mecz L, Marmur S, Ben-Shachar D, Feinsod M (1999) Therapeutic efficacy of right prefrontal slow repetitive transcranial magnetic stimulation in major depression: a doubleblind controlled study. Arch Gen Psychiatry 56:315-320.

Knecht S, Ellger T, Breitenstein C, Bernd Ringelstein E, Henningsen H (2003) Changing cortical excitability with low-frequency transcranial magnetic stimulation can induce sustained disruption of tactile perception. Biol Psychiatry 53:175-179.

Kosslyn SM, Pascual-Leone A, Felician O, Camposano S, Keenan JP, Thompson WL, Ganis G, Sukel KE, Alpert NM (1999) The role of area 17 in visual imagery: convergent evidence from PET and rTMS. Science 284:167-170.

Larson J, Lynch G (1986) Induction of synaptic potentiation in hippocampus by patterned stimulation involves two events. Science 232:985-988.

Larson J, Wong D, Lynch G (1986) Patterned stimulation at the theta frequency is optimal for the induction of hippocampal long-term potentiation. Brain Res 368:347-350.

Lemon RN (1993) The G. L. Brown prize lecture. Cortical control of the primate hand. Exp Physiol 78:263-301.

Muellbacher W, Ziemann U, Wissel J, Dang N, Kofler M, Facchini S, Boroojerdi B, Poewe W, Hallett M (2002) Early consolidation in human primary motor cortex. Nature 415:640-644.

Munchau A, Bloem BR, Thilo KV, Trimble MR, Rothwell JC, Robertson MM (2002) Repetitive transcranial magnetic stimulation for Tourette syndrome. Neurology 59:1789-1791.

Rioult-Pedotti MS, Friedman D, Hess G, Donoghue JP (1998) Strengthening of horizontal cortical connections following skill learning. Nat Neurosci 1:230-234.

Rioult-Pedotti MS, Friedman D, Donoghue JP (2000) Learning-induced LTP in neocortex. Science 290:533-536.
Rothwell J, Burke D, Hicks R, Stephen J, Woodforth I, Crawford M (1994) Transcranial electrical-stimulation of the motor cortex in man-further evidence for the site of activation. J Physiol (Lond) 481:243-250.

Rothwell JC, Thompson PD, Day BL, Boyd S, Marsden CD (1991) Stimulation of the human motor cortex through the scalp. Exp Physiol 76:159-200.

Siebner HR, Tormos JM, Ceballos-Baumann AO, Auer C, Catala MD, Conrad B, Pascual-Leone A (1999) Low-frequency repetitive transcranial magnetic stimulation of the motor cortex in writer's cramp. Neurology 52:529-537.

Tergau F, Naumann U, Paulus W, Steinhoff BJ (1999) Low-frequency repetitive transcranial magnetic stimulation improves intractable epilepsy. Lancet 353:2209.

Theodore WH, Hunter K, Chen R, Vega-Bermudez F, Boroojerdi B, ReevesTyer P, Werhahn K, Kelley KR, Cohen L (2002) Transcranial magnetic stimulation for the treatment of seizures: a controlled study. Neurology 59:560-562.

Thompson PD, Rothwell JC, Day BL (1989) Mechanisms of electrical and magnetic stimulation of human motor cortex. In: Magnetic stimulation in clinical neurophysiology (Chokroverty S, ed), pp 121-143. Stoneham, MA: Butterworth.

Touge T, Gerschlager W, Brown P, Rothwell JC (2001) Are the after-effects of low-frequency rTMS on motor cortex excitability due to changes in the efficacy of cortical synapses? Clin Neurophysiol 112:2138-2145.

Wassermann EM (2002) Variation in the response to transcranial magnetic brain stimulation in the general population. Clin Neurophysiol 113:1165-1171.

Wassermann EM, Lisanby SH (2001) Therapeutic application of repetitive transcranial magnetic stimulation: a review. Clin Neurophysiol 112:1367-1377.

Wassermann EM, Cohen LG, Flitman SS, Chen R, Hallett M (1996a) Seizures in healthy people with repeated "safe" trains of transcranial magnetic stimuli. Lancet 347:825-826.

Wassermann EM, Grafman J, Berry C, Hollnagel C, Wild K, Clark K, Hallett M (1996b) Use and safety of a new repetitive transcranial magnetic stimulator. Electroencephalogr Clin Neurophysiol 101:412-417.

Ziemann U, Lonnecker S, Steinhoff BJ, Paulus W (1996) Effects of antiepileptic drugs on motor cortex excitability in humans: a transcranial magnetic stimulation study. Ann Neurol 40:367-378. 